\title{
Proposta curricular emancipadora versus movimento (conservador) Escola sem Partido
}

\author{
Eraldo Leme Batista \\ Ana Paula Noffke
}

Resumo: Neste artigo apresentamos estudos e análise referente ao processo de organização, debate e implementação de um currículo que abrangesse todas as escolas públicas do Estado do Paraná, Região Oeste do Estado. Verificamos em nossa pesquisa que foi um processo rico de debate entre professores que participaram desse processo, culminando com a aprovação do projeto. Constatamos que essa investidura só teve êxito em decorrência do empenho de educadores que acreditaram na possibilidade de concretizar essa proposta. Demonstramos a importância da construção de um currículo fundamentado na perspectiva filosófica clássica, conteudista e omnilateral. Se o currículo construído na Região Oeste do Paraná defende o saber elaborado, clássico, vemos ao mesmo tempo, movimento de expressão nacional, como o Escola Sem Partido, defender educação sem fundamentação filosófica, teórica, além de defenderem uma escola não estatal, não gratuita, não laica e não científica.

Palavras-chave: Currículo. Educação. Organização pedagógica. Ideologia.

\section{Proposal for a curriculum aimed at empowerment versus a (conservative) party-free school movement}

\begin{abstract}
This article presents studies and an analysis related to the process of organizing, debating and implementing a curriculum aimed at all public schools of the Western Region of the State of Paraná, Brazil. Our research shows that this process was widely discussed among teachers who took part in it, culminating in the approval of the project. We are aware of the fact that this achievement was only successful due to educators' commitment who believe in the possibility of putting this proposal into practice. The article further shows how essential it is to build a curriculum based on the classical philosophical perspective, i.e. a multi-lateral one based on contents. Although the curriculum built in the Western Region of Paraná advocates elaborate, classical knowledge, we also notice that there is a movement of national expression, i.e. the Party-Free School, that endorses education without any philosophical and theoretical foundation, sustaining a paid non-state, non-secular and unscientific school model.
\end{abstract}

Keywords: Curriculum. Education. Pedagogical organization. Ideology. 
BATISTA, Eraldo Leme; NOFFKE, Ana Paula. Proposta curricular emancipadora versus movimento (conservador) escola sem partido.

A partir de 2007, as escolas públicas municipais da Região Oeste do Paraná passaram a ter um currículo próprio, construído coletivamente durante os anos de 2005 e 2006, pelo colegiado de educadores daquela região, coordenado por um grupo representativo dos diferentes níveis de ensino, e também, no tocante ao ensino superior, das esferas pública e privada. Após dois anos de muitos estudos e debates, o Currículo Básico para a Escola Pública Municipal foi publicado pelo Departamento Pedagógico da Associação dos Municípios do Oeste do Paraná $\mathrm{AMOP}^{1}$, sendo, a partir de então, o norteador do trabalho docente para as escolas públicas municipais dos associados daquela entidade.

Conforme se apresenta em seus pressupostos, trata-se de um instrumento fundamentado em uma concepção dialética de educação e, portanto, compreende que "o ato pedagógico não é neutro: carrega implicações sociais, está marcado pela prática de todos os envolvidos no processo educativo e é mediado por relações sócio históricas” (AMOP, 2007, p. 28). O Currículo Básico da AMOP se fundamenta na concepção filosófica materialista histórico-dialética, partindo de três pressupostos:

[...] o primeiro é o de que a realidade não é estática, pois se encontra em constante movimento, ou seja, está em constante devir, em constante vir a ser e que, portanto, tudo o que existe hoje não existiu, não existe e não existirá da mesma forma; o segundo é que é preciso estar vivo para fazer história, e quem faz a história é o próprio homem; o terceiro é que a base da sociedade está fundada no trabalho. Esses três pressupostos marcam a vida do homem e estabelecem seus limites e suas possibilidades (AMOP, 2007, p. 28).

Isto posto, faz-se importante compreendemos que o materialismo histórico-dialético tem como categorias centrais o trabalho, a totalidade, a historicidade, a contradição, o movimento, a mediação e a superação.

O Currículo da AMOP está presente na educação das redes municipais de ensino dos municípios associados àquela entidade, tendo essa concepção filosófica fundamentado as formações dos educadores de tais redes. Entendemos que um trabalho pautado numa concepção crítica de educação requer o aprofundamento dos estudos sobre o método materialista históricodialético, considerando que não "podemos descuidar dos pressupostos, das concepções e dos fundamentos teórico-metodológicos que sempre embasam a prática educacional” (AMOP, 2007, p. 34). E, em especial, porque trata-se de um método que "não pode ser compreendido fora do

\footnotetext{
${ }^{1}$ O Currículo Básico para a Escola Pública Municipal da região Oeste do Paraná é conhecido como Currículo da AMOP. Desta forma, será assim que o denominaremos neste artigo.
} 
BATISTA, Eraldo Leme; NOFFKE, Ana Paula. Proposta curricular emancipadora versus movimento (conservador) escola sem partido.

conjunto do pensamento marxista" (GADOTTI, 1983, p. 33). Em decorrência disso, o trabalho docente, tendo este material como alicerce, demanda de estudos que nos possibilitem uma compreensão de que a educação se refere ao conjunto das relações sociais e humanas estabelecidas na prática social de uma sociedade, em uma determinada época, considerando a totalidade das relações e condições na busca e na transmissão do conhecimento. Afinal, na escola estão presentes as relações universais (ORSO, 2011).

Por estar pautado nesta concepção filosófica, o Currículo Básico da AMOP traz em seus pressupostos pedagógicos elementos da Pedagogia Histórico-Crítica (PHC), apresentada por Batista e Lima (2012, p. 1-2) como um "importante instrumental na superação da unilateralidade humana”. Trata-se de uma concepção pedagógica que propõe

[...] a ação pedagógica fundamentada na articulação entre teoria e prática (práxis), contribuindo para que os indivíduos ultrapassem a visão imediata dos fenômenos. [...] um projeto comprometido com a transformação social, ancorado na prática educativa questionadora, crítica e emancipadora (BATISTA; LIMA, 2012, p. 1-2).

Diante disso, nessa concepção pedagógica os conteúdos são fundamentais, pois compreende-se que é por meio deles que as camadas populares poderão fazer valer os seus interesses e buscar a emancipação da classe trabalhadora. A educação, entendida como trabalho e, portanto, como princípio educativo, deve contribuir para a humanização, e, desta forma, o trabalho educativo é considerado "o ato de produzir direta e intencionalmente, em cada indivíduo singular, a humanidade que é produzida histórica e coletivamente pelo conjunto dos homens" (SAVIANI, 2008, p. 13). Assim, o currículo precisa contemplar "a multidimensionalidade do conhecimento", objetivando "a humanização na perspectiva de tornar a classe trabalhadora" em classe para si (AMOP, 2007, p. 59).

As políticas públicas municipais para essa formação não podem ser compostas de eventos pontuais, especialmente quando comprometidos com a ideologia empresarial de qualidade total e a de empreendedorismo, entendidas como responsabilidade do diretor ou dos especialistas que atuam na escola. Nem podem ficar submetidas à mudança de governo. [...] A formação a que nos referimos só ganhará caráter de continuidade se propiciar um processo de aprofundamento epistemológico. Promover esse tipo de formação é valorizar o trabalhador em educação. Esse modo de formação pode estar previsto, inclusive, nos Planos Municipais de Educação e pode ser resultado da participação efetiva dos trabalhadores no planejamento dessa prática formativa (AMOP, 2007, p. 59).

O Currículo Básico da AMOP é fruto de muitos estudos e debates, ocorridos entre os anos de 2005 e 2006, em que educadores da região se reuniram em várias ocasiões no intuito de 
BATISTA, Eraldo Leme; NOFFKE, Ana Paula. Proposta curricular emancipadora versus movimento (conservador) escola sem partido.

construírem uma proposta curricular coletiva e democrática que possibilitasse não apenas de explicar como funciona a sociedade, mas que fosse um instrumento que tornasse possível pensar na transformação dessa sociedade (AMOP, 2007).

A escolha pelas concepções filosófica e pedagógica que fundamentam o currículo ocorreu logo nas primeiras discussões do coletivo de educadores, que optaram por retomar os princípios do Currículo Básico do Paraná, no que se refere à concepção de homem, educação e sociedade (AMOP, 2007). Portanto, trata-se de um documento elaborado por aqueles que estão no chão da escola pública, vivenciando as agruras do magistério em uma das sociedades mais desiguais do mundo. O Currículo Básico da AMOP não foi uma política imposta, mas construída coletivamente. O material já passou por duas avaliações, estando na sua $3^{\text {a }}$ edição. Algumas mudanças foram efetuadas, porém os pressupostos permanecem os mesmos, preservando as concepções apresentadas na primeira publicação.

A adoção de um currículo pautado no materialismo histórico-dialético e, portanto, de uma pedagogia progressista, tomada pelos educadores da região Oeste do Paraná, se contrapõe, em certa medida, ao conservadorismo, uma vez que parte de uma análise crítica da realidade social, sustentando, implicitamente, as finalidades sociopolíticas da educação. Sendo a escola constituída por um conjunto de contradições e por disputas de concepções de mundo, esse currículo pretende romper com o caráter reprodutivista.

Uma das contradições virtuosas próprias à educação escolar é exatamente o fato de que o acesso ao conhecimento sistematizado pela classe trabalhadora possibilita a essa classe compreender o mundo e ampliar sua capacidade de transformá-lo, primeiramente no plano mais imediato de suas vidas e, mediatamente, por meio de sua organização coletiva (RAMOS, 2017, p. 81).

O acesso ao conhecimento por parte da classe trabalhadora se torna força material na luta social. Concomitantemente, "a construção da unidade necessária entre sujeitos de uma classe ou grupo social na prática política é pedagógica e abre perspectiva para práticas educativas”, à medida que a unidade se reflete em "condições subjetivas vinculadas ao acesso à informação, ao conhecimento e à cultura" (RAMOS, 2017, p. 81).

Por isso se compreende a impossibilidade de separação da educação e da política. Logo, toda prática educativa contém uma dimensão política e toda prática política contém uma dimensão educativa (SAVIANI, 1988; RAMOS 2017). 
BATISTA, Eraldo Leme; NOFFKE, Ana Paula. Proposta curricular emancipadora versus movimento (conservador) escola sem partido.

Em pesquisa intitulada “Antecedentes Históricos do Currículo da AMOP”, Noffke (2017) apresenta como se constituiu o movimento de educadores progressistas na região Oeste do Paraná, tendo reflexos diretos na concepção filosófica deste currículo. É importante salientar que, sendo a educação um espaço de disputa, a narrativa histórica apresentada pela autora mostra avanços e retrocessos neste movimento. Contudo, a formação continuada de professores das redes municipais da região Oeste coordenada pelo Departamento Pedagógico da AMOP, tem seguido à concepção filosófica e pedagógica assumida pelo coletivo de educadores, com os estudos iniciados em 2005, para a elaboração da primeira edição do documento.

Contudo, justamente por ser a educação um espaço de disputa, há um risco iminente a todo o trabalho que vem sendo realizado pelos educadores em questão, provocado por um movimento conservador, denominado Escola Sem Partido.

\section{Movimento escola sem partido}

O Movimento Escola Sem Partido (MESP) foi criado em 2004, por uma questão pessoal, por um advogado, Miguel Nagib, em resposta ao que ele interpretou como "doutrinação" por parte de um professor de sua filha. Segundo Nagib, que também é procurador do Estado de São Paulo, o professor teria feito uma comparação entre São Francisco de Assis e o revolucionário Che Guevara, um dos líderes da revolução cubana. A analogia feita pelo professor consistiu em demonstrar para os alunos duas pessoas que se despojaram de seus bens em nome de uma causa. No caso de Francisco de Assis, uma causa religiosa; já o revolucionário tinha uma causa ideológica política. Contudo, o advogado interpretou como se o professor estivesse dizendo que Che Guevara é um santo: “[...] as pessoas que querem fazer a cabeça das crianças associam as duas coisas e acabam dizendo que Che Guevara é um santo [...]” (BEDINELLI, 2016, s. p.). Indignado, Miguel Nagib elaborou uma carta e distribuiu aos pais dos estudantes da escola de sua filha. A direção escolar o chamou para fazer esclarecimentos, e depois disso o advogado afirma que sofreu ofensas por parte dos apoiadores do professor (BEDINELLI, 2016).

Este movimento passou uma década sem expressividade e apoio, principalmente por ser considerado inconstitucional. Contudo, em 2014, ano seguinte aos grandes protestos ocorridos no país, durante o governo de Dilma Rousseff (PT), foi apresentado na Assembleia Legislativa do Estado do Rio de Janeiro o primeiro projeto de lei do Programa Escola Sem Partido. O PL 
BATISTA, Eraldo Leme; NOFFKE, Ana Paula. Proposta curricular emancipadora versus movimento (conservador) escola sem partido.

2.974/2014 (RIO DE JANEIRO, 2014) foi apresentado por Flávio Bolsonaro, no dia 15 de maio de 2014, propondo a criação do Programa Escola Sem Partido, no âmbito do Sistema de Ensino do Estado do Rio de Janeiro. Na sequência, em 3 de junho daquele ano, o irmão do deputado, o vereador Carlos Bolsonaro, também apresentou um projeto semelhante, PL 867/2015 (BRASIL, 2015), na Câmara Municipal do Rio de Janeiro, com o mesmo propósito. Tais projetos repercutiram em âmbito nacional, sendo que até o final de 2014 foram apresentados 18 projetos de lei dessa natureza. Em 2015, foram 17 projetos e em 2016, 14 (MOURA, 2016).

Ao analisar o discurso do Movimento Escola Sem Partido (MESP), Moura (2016) verificou o seu alinhamento aos ideais conservadores, apresentados por Botelho e Ferreira (2010, p. 12), como “a importância dada à religião; a valorização das associações intermediárias situadas entre o Estado e os indivíduos (família, aldeia tradicional, corporação) e a correlata crítica à centralização estatal e ao individualismo moderno", assim como "o apreço às hierarquias e a aversão ao igualitarismo em suas várias manifestações; o espectro da desorganização social visto como consequência das mudanças vividas pela sociedade ocidental”. Os autores destacam a importância do pensamento conservador como um componente da tradição intelectual do país, sendo também uma força político-social na sociedade brasileira.

[...] como se constituiu no Brasil uma cultura política que menospreza a monumental desigualdade que marca a nossa sociedade. E, sobretudo, porque avessa à democracia, não acredita na ação coletiva e favorece que o homem comum não leve a sério os seus iguais (BOTELHO; FERREIRA, 2010, p. 14).

Com um discurso explicitamente conservador, o MESP ganhou visibilidade, com a proposição de medidas para impedir que educadores expressem opiniões consideradas impróprias pelo movimento, em sala de aula. O MESP se apresenta como uma "iniciativa conjunta de estudantes e pais preocupados com o grau de contaminação político ideológica das escolas brasileiras, em todos os níveis: do ensino básico ao superior" (MIGUEL, 2016, p. 595).

Quase inexpressivo na sua primeira década de existência, após os grandes protestos de 2013 o MESP passou a ganhar espaço nos debates sobre educação no Brasil. Tem em seu programa o apoio da direita brasileira e vem sendo o idealizador de projetos de lei que tramitam nas Câmaras de Vereadores e Assembleias Legislativas, e também no Congresso Nacional. Com a mudança de governo, após o golpe parlamentar de 2016, o novo ministro da Educação, Mendonça Filho, apresentou simpatia à proposta do MESP (MIGUEL, 2016). 
BATISTA, Eraldo Leme; NOFFKE, Ana Paula. Proposta curricular emancipadora versus movimento (conservador) escola sem partido.

Na apresentação do movimento exposta no site Escola Sem Partido, o coordenador afirma que "a pretexto de transmitir aos alunos uma 'visão crítica' da realidade, um exército organizado de militantes travestidos de professores prevalece-se da liberdade de cátedra e da cortina de segredo das salas de aula para impingir-lhes a sua própria visão de mundo" (NAGIB, 2017). De acordo com o texto, a inspiração para a criação do movimento veio dos Estados Unidos, onde uma ação semelhante já havia ganhado corpo. A partir disso, os idealizadores brasileiros decidiram criar "uma associação informal, independente, sem fins lucrativos e sem qualquer espécie de vinculação política, ideológica ou partidária” (NAGIB, 2017). Miguel Nagib, no entanto, omite uma informação importante, que coloca em xeque o caráter do movimento do qual é o principal idealizador.

Em trabalho de Aquino (2016), a autora apresenta dados que comprovam forte vínculo entre o procurador o Instituto Millenium ${ }^{2}$, "o principal think tank"3 da direita brasileira (MIGUEL, 2016, p. 593). Este instituto foi criado em 2006, sendo financiado por empresas nacionais e transnacionais, "com eco na linha editorial de parte da grande imprensa e popularizada por jornalistas como Rodrigo Constantino" (MIGUEL, 2016, p. 593). Em um texto de Nagib para o Instituto, denominado "Por uma escola que promova os valores do Millenium", o autor apresenta os valores que deveriam ser ensinados por esta escola: "propriedade privada", "responsabilidade individual" e "meritocracia". Esses valores não podem ser considerados neutros (PENNA, 2017, p. 40).

Em busca por mais informações sobre a Associação Escola Sem Partido, pessoa jurídica do MESP, Moura (2016, p. 24) encontrou "uma segunda pessoa jurídica: Escola Sem Partido Treinamento e Aperfeiçoamento Eireli - ME”.

Esta seria uma Empresa Individual de Responsabilidade Limitada de Natureza Empresária do procurador Miguel Nagib e seu ramo de atividade seria treinamento em desenvolvimento profissional e gerencial que tem um capital de quase oitenta mil reais. Portanto, a apresentação do MESP como apenas "uma iniciativa conjunta de estudantes e pais preocupados com o grau de contaminação político-ideológica das escolas brasileiras" (ESCOLA SEM PARTIDO, 2014-2017), como consta no site, vai de

\footnotetext{
${ }^{2}$ As ligações do procurador com o Instituto foram investigadas por Aquino em artigo do Blog Liberdade para Ensinar, assinado por Renata Aquino, com o Título A Ideologia do Escola Sem Partido.

${ }^{3}$ Um Think-Tank é em geral um grupo de interesse ou uma instituição que investe em divulgação e propagação de conhecimento com viés político-ideológico definido e ligado a interesses particulares deste grupo, visando transformações na sociedade.
} 
BATISTA, Eraldo Leme; NOFFKE, Ana Paula. Proposta curricular emancipadora versus movimento (conservador) escola sem partido.

encontro à sua proximidade ideológica com a corrente liberal e o desenvolvimento de suas atividades empresariais, que contradizem uma neutralidade defendida publicamente (MOURA, 2016, p. 24).

Tais informações sustentam a posição apresentada no Currículo Básico da AMOP, de que a educação é um ato político, e que, portanto, “carrega implicações sociais" e está "marcado pela prática de todos os envolvidos no processo educativo" (AMOP, 2007). Compreende-se, portanto, que educação e política formam uma unidade, apesar de serem processos distintos, pois "as sociedades de classe se caracterizam pelo primado da política, o que determina a subordinação real da educação à prática política" (SAVIANI, 1988, p.99). Isto está manifesto na educação brasileira.

Não existe neutralidade em nenhuma relação, posto que a educação, necessariamente e sempre, será guiada por alguma filosofia, por uma concepção de mundo, mesmo que esses não sejam explicitados nos respectivos projetos político-pedagógicos ou que seus sujeitos não tenham plena consciência dos mesmos. Não é por acaso, então, que o movimento dirige seus ataques predominantemente às faculdades de educação, o lugar da formação filosófica em educação por excelência (RAMOS, 2017, p. 81).

O MESP tem um posicionamento político-ideológico que se choca frontalmente com uma perspectiva crítica de educação, pautada por uma concepção filosófica defendida nos pressupostos do Currículo Básico da AMOP (AMOP, 2007). A impossibilidade de separação da educação e da política se expressa no fato de "o currículo escolar ser alvo de disputa das classes e um processo de seleção cultural e ideológica” (RAMOS, 2017, p. 81).

O Escola sem Partido é a própria comprovação deste fato. Trata-se de tentar imprimir ao currículo escolar sua ideologia a qual, enunciada como neutra é, na verdade, totalmente comprometida com a classe dominante, pois impede que os interesses dos dominados sejam abordados na escola (RAMOS, 2017, p. 81-82).

A continuidade do dualismo na educação brasileira, com uma escola pobre para pobres, se explica pela desigualdade na distribuição do conhecimento. Por isso, controlar essa distribuição se faz necessário. E isso é o que intenta o Escola sem Partido, ou seja, "controlar particularmente as políticas curriculares e a prática pedagógica da escola pública” (RAMOS, 2017, p. 82). Para seus propugnadores, professores oriundos das camadas populares ou "intelectuais de esquerda" que atuam nessas escolas são uma ameaça à ordem. "Daí controlá-los, persegui-los e criminalizálos" (RAMOS, 2017, p. 82). 
BATISTA, Eraldo Leme; NOFFKE, Ana Paula. Proposta curricular emancipadora versus movimento (conservador) escola sem partido.

O motivo originário de fundação do movimento foi a "doutrinação marxista", no entanto, ele foi reforçado com o apoio da pauta da bancada evangélica contra a denominada "ideologia de gênero".

A fusão da denúncia da doutrinação marxista de inspiração gramsciana com a oposição à "ideologia de gênero" obedeceu, assim, ao senso de oportunidade do MESP. Deu a ele aliados de peso, uma capilaridade com a qual nem poderia sonhar e um discurso com ressonância popular muito mais imediata. A confluência foi facilitada graças ao trabalho de propagandistas da extrema-direita, em particular os alinhados a Olavo de Carvalho, para quem a dissolução da moral sexual convencional é um passo da estratégia comunista (MIGUEL, 2016, p. 601).

O movimento ganhou maior expressividade em 2014, com a crise política e a polarização da sociedade com as campanhas presidenciais à Presidência da República de Dilma Rousseff e Aécio Neves.

A oposição ao governo Dilma [...] responsabilizou o partido da então presidenta pela suposta doutrinação "comunista-homossexual". Desde o início do processo de impeachment contra a presidenta, no final de 2015, o MESP parece ter alcançado ainda mais destaque, uma vez que a denúncia pelos professores de ruptura da ordem democrática era respondida pelo movimento como abuso da liberdade de ensinar e doutrinação política e ideológica (MOURA, 2016, p. 28).

Contudo, adverte a autora, "não se deve de forma alguma reduzir o debate sobre o Movimento Escola Sem Partido e os projetos a ele relacionados à dimensão político-partidária" (MOURA, 2016, p. 29). Trata-se de uma questão maior, relacionada direta e fundamentalmente com uma disputa entre dois projetos de sociedade, um progressista e outro conservador.

Neste sentido, o projeto conservador apresentado pelo MESP defende a necessidade de limitação à autonomia docente. Porém, o mais grave é a forma como fazem isso. Seus propugnadores manifestam-se de forma arrogante, sem nenhuma ética nem respeito com os educadores e a sociedade em geral, com um discurso supostamente neutro, camuflando um teor fortemente persecutório, repressor e violento (RAMOS, 2017). Em sua página na internet (ESCOLA SEM PARTIDO, 2017), o movimento dispõe documentos como "modelo de notificação extrajudicial" ao professor, além de orientações nesse sentido, tais como "flagrando o doutrinador" e "planeje sua denúncia".

Em âmbito federal, tramita na Câmara de Deputados o PL 867/2015 (BRASIL, 2015), de autoria do deputado Izalci Lucas Ferreira (PSDB-DF), que propõe a inclusão do Programa Escola Sem Partido, entre as diretrizes e bases da educação nacional. Mas o que vem a propor esse 
BATISTA, Eraldo Leme; NOFFKE, Ana Paula. Proposta curricular emancipadora versus movimento (conservador) escola sem partido.

programa? Penna (2017) apresenta quatro características fundamentais para compreendermos esse fenômeno: a concepção de escolarização; desqualificação do professor; estratégias discursivas fascistas; defesa do poder total dos pais sobre os filhos.

O autor apresenta a concepção de escolarização, e não de educação, porque o Programa faz uma dissociação entre o ato de educar e o ato de instruir. O primeiro caberia à família e à religião. Dessa forma, o professor deve limitar-se a instruir, "o que no discurso do Escola sem Partido equivale a transmitir conhecimento neutro, sem mobilizar valores e sem discutir a realidade do aluno" (PENNA, 2017, p. 36).

Outra característica apontada pelo autor em relação à concepção de escolarização é de que o professor não pode falar sobre a realidade do aluno. O PL 867/2015 (BRASIL, 2015), propõe a proibição da prática da doutrinação política e ideológica em sala de aula. Contudo, em nenhum momento do projeto, seus autores definem “doutrinação política e ideológica”, caracterizando em inconstitucionalidade. Ora, para proibir uma prática é preciso defini-la precisamente (PENNA, 2017). A definição pode ser encontrada no site do MESP, pelos ícones "Flagrando o doutrinador" e "Planeje a sua denúncia". Há uma orientação para o aluno de como ele pode fazer a sua denúncia anotando o dia, o horário, e coisas assim. É apresentada uma lista de atividades para que o aluno possa reconhecer o professor doutrinador (PENNA, 2017).

Para se reconhecer vítima de doutrinação, o aluno deve verificar se o professor desvia do objeto de estudo da disciplina para assuntos relacionados ao noticiário político ou internacional. Ou seja, deve haver uma dissociação entre o conteúdo e o que está acontecendo no mundo, na realidade do aluno.

A afirmativa de que o professor não poderia discutir essa realidade, ele teria que se ater à sua matéria - e nós sabemos que isso na prática é impossível, porque dialogar com a realidade do aluno é um princípio educacional estabelecido para tornar o ensino das disciplinas significativo (PENNA, 2017, p. 37).

O MESP coloca, ainda, como característica de um professor doutrinador aquele que "adota ou indica livros e publicações de autores identificados com determinada corrente ideológica", como se pudesse haver um livro que se identifica com uma corrente ideológica. Isso demonstra que o Programa faz uma dissociação questionável entre ideologia e neutralidade. E outra característica do professor doutrinador, apresentada pelos defensores do movimento, é a imposição a leitura de textos, e a apresentação de uma única visão sobre o tema, tratando o 
BATISTA, Eraldo Leme; NOFFKE, Ana Paula. Proposta curricular emancipadora versus movimento (conservador) escola sem partido.

professor como um manipulador. Miguel Nagib defende a ideia de que o professor não pode falar de nenhum valor em sala de aula, a não ser aqueles necessários à transmissão do conhecimento. O professor transmite conhecimento, porém não discute valores e não pode falar sobre a realidade do aluno: essa é a concepção de escolarização apresentada no PESP (PENNA, 2017, p. 37).

Como característica do Programa, percebe-se uma forte desqualificação do professor. Para Penna (2017) essa lógica de desqualificação do professor se aproxima do que poderíamos chamar de uma lógica de mercado, a qual consiste em pensar a educação como uma relação entre alguém que está prestando um serviço e um consumidor. E isso é melhor compreendido quando Miguel Nagib afirma que sua inspiração para a elaboração do projeto Escola sem Partido foi o código de defesa do consumidor. Trata-se de "uma tentativa evidente de pensar a educação como uma relação de consumo" (PENNA, 2017, p. 39).

O PESP defende em seu segundo princípio o "pluralismo de ideias no ambiente acadêmico", diferentemente como aparece na Constituição Federal de 1988, ou seja, como "pluralismo de ideias e de concepções pedagógicas, e coexistências de instituições públicas e privadas de ensino". Percebe-se a exclusão intencionalmente do pluralismo de concepções pedagógicas. O terceiro princípio estabelecido no PL do ESP defende "a liberdade de aprender como projeção específica no campo da educação da liberdade de consciência". No texto da CF, Inciso II, do artigo 206, estabelece a "liberdade de aprender, ensinar, pesquisar, divulgar o pensamento, a arte e o saber". Houve a exclusão intencional do termo "liberdade de ensinar". Percebe-se que os propugnadores do PESP estão excluindo todas as atribuições vinculadas à atividade profissional do professor, ou seja, à docência (PENNA, 2017, p. 41).

Excluíram o pluralismo de concepções pedagógicas, excluíram a liberdade de ensinar, e eles vão mais longe e propõem a exclusão da liberdade de expressão. Então, na sua justificação, [...], eles afirmam literalmente que "não existe liberdade de expressão no exercício estrito da atividade docente, sob pena de ser anulada a liberdade de consciência e crença dos estudantes, que formam em sala de aula uma audiência cativa". São nossos prisioneiros. Segundo essa interpretação, o professor seria a única categoria profissional no Brasil que não teria liberdade de expressão no exercício da sua atividade profissional (PENNA, 2017, p. 41).

O PL 867/2015 (BRASIL, 2015) tramita apensado ao PL 7.180/2014 (BRASIL, 2014), de autoria do deputado Erivelton Santana ${ }^{4}$, da Bahia, que "altera o art. $3^{\circ}$ da Lei $n^{\circ} 9.394$, de 20 de

\footnotetext{
${ }^{4}$ Erivelton Santana era filiado ao PSC na ocasião da apresentação do PL à Câmara dos Deputados, e hoje pertence ao PEN.
}

Quaestio, Sorocaba, SP, v. 20, n. 3, p. 601-615, dez. 2018 
BATISTA, Eraldo Leme; NOFFKE, Ana Paula. Proposta curricular emancipadora versus movimento (conservador) escola sem partido.

dezembro de 1996" e "dispõe sobre a fixação de parâmetros curriculares nacionais em lei com vigência decenal". De acordo com o PL, "a educação escolar, promovida em instituições de ensino básico, será orientada por parâmetros curriculares nacionais, estabelecidos em lei e com vigência decenal" (BRASIL, 2015).

Os parâmetros curriculares nacionais respeitarão as convicções dos alunos, de seus pais ou responsáveis, tendo os valores de ordem familiar precedência sobre a educação escolar nos aspectos relacionados à educação moral, sexual e religiosa, vedada a transversalidade ou técnicas subliminares no ensino desses temas (BRASIL, 2014, p. 1)

O autor deste PL cursou parcialmente a Licenciatura em História, pela Universidade Católica de Salvador e integra a Frente Parlamentar Evangélica (FPE) como representante da Igreja Evangélica Assembleia de Deus. É de sua autoria, ainda, o PL 5.618-A/2013 (BRASIL, 2013), que autoriza o poder executivo a transformar em projeto de Estado o programa denominado "Fé na Prevenção", que levaria os agentes religiosos, dentre outras coisas, a "participar da implantação de projetos pedagógicos de prevenção do uso indevido de drogas, nas instituições de ensino de que trata a Lei n 9 9.394, de 20 de dezembro de 1996" (BRASIL, 2014, p. 3). Em outras palavras, grupos religiosos fariam seu "trabalho educativo" nas instituições de educação básica, inclusive públicas (MOURA, 2016, p. 34).

Ramos (2017) chama a atenção para o fato, não casual, de que os temas a que esse grupo se refere como os mais permeáveis à doutrinação ideológica sejam raça e etnia, religiosidade, sexualidade e gênero, capitalismo e socialismo. Para a autora

[...] a proposta é, na verdade, de uma "escola partida". Isto porque, se educação e política podem ser vistos como "irmãos siameses", isto é, como uma relação de unidade, mas não de identidade, ao tentar separá-los, querem sacrificar a política, supostamente salvando a educação. Porém, este ser sobrevivente, como não pode viver sem a unidade que o constitui, retém a face desfigurada do irmão sacrificado: a doutrina conservadora (RAMOS, 2017, p. 77).

A denominação "sem partido" se aproveita da reação que a sociedade brasileira mostra em relação aos partidos políticos, para seduzir e conseguir a adesão dos cidadãos às ideias apresentadas pelo MESP. Provoca-se um esvaziamento do sentido da política, a fim de conferir o poder aqueles que "historicamente oprimem os que não se enquadram nos padrões hegemônicos de uma classe dominante autoritária e escravocrata" (RAMOS, 2017, p. 85). A iniciativa de Miguel Nagib é ardilosa desde o título, escondendo "uma poderosa teia de relações que surpreende pelo cunho conservador, com várias articulações e redes que perpassam por entidades 
BATISTA, Eraldo Leme; NOFFKE, Ana Paula. Proposta curricular emancipadora versus movimento (conservador) escola sem partido.

da sociedade civil, instâncias religiosas e partidos políticos” (ESPINOSA; QUEIROZ, 2017, p. 49).

\section{Considerações finais}

Impossibilidade de coexistência de um Currículo para uma educação crítica e o Programa Escola Sem Partido. A adesão ao PESP por parte de algum município da região oeste significará o desrespeito à decisão coletiva dos educadores por um currículo pautado numa perspectiva emancipadora de educação, que possibilite a leitura da realidade para além da aparência. $\mathrm{O}$ Currículo Básico da AMOP foi construído coletivamente, demandando muitos estudos e debates. O PESP é um projeto imposto por pessoas que não fazem parte diretamente da educação, pessoas que estão distantes, portanto, da realidade educacional pública brasileira, considerando-se a amplitude e complexidade inerentes a ela.

A partir dos estudos que realizamos, constatamos que o movimento político e ideológico Escola Sem Partido, é um movimento vinculado a um projeto conservador de sociedade e de educação. Aliás, constatamos que os elaboradores e principais defensores e articuladores desse movimento e das ideias presentes no projeto ESP não são vinculados à educação, mas sim à grupos e partidos políticos privatistas, conservadores, de direita. Percebemos que quando em período histórico avançam as ideias e propostas por uma educação pública, estatal, gratuita, laica, para todos, de qualidade, surge um movimento oposto, defendendo o esvaziamento de conteúdo e de conhecimento, menosprezando o trabalho docente e a formação de professores. O saber científico, clássico, humanista, foi produzido pelo homem no decorrer da história, sendo sistematizado pelo mesmo, portanto é o mesmo fruto da produção humana na história da humanidade e todos os seres humanos devem ter o direito e o acesso ao mesmo.

\section{Referências}

AMOP. Currículo básico para a Escola Pública Municipal: educação infantil e ensino fundamental (anos iniciais). Cascavel: ASSOESTE, 2007.

AQUINO, R. A ideologia do Escola Sem Partido. Instituto Millenium - Movimento liberdade para educar. Rio de Janeiro, 2016. Disponível em: <https://liberdadeparaensinar.wordpress. com/tag/institutomillenium/>. Acesso em: 16 jun. 2017. 
BATISTA, Eraldo Leme; NOFFKE, Ana Paula. Proposta curricular emancipadora versus movimento (conservador) escola sem partido.

BATISTA, E. L.; LIMA, M. R. A pedagogia histórico-crítica como teoria pedagógica transformadora: da consciência filosófica à prática revolucionária. In: MARSIGLIA, A. C. G.; BATISTA, E. L. (Org.). Pedagogia histórico-crítica: desafios e perspectivas para uma educação transformadora. Campinas: Autores Associados, 2012.

BEDINELLI, T. O professor da minha filha comparou Che Guevara a São Francisco de Assis. El País Brasil, Política, São Paulo, 26 jun. 2016. Disponível em: <https://brasil.elpais.com/brasil/2016/06/23/ politica/1466654550_367696.html>. Acesso em: 18 ago. 2017.

BOTELHO, A.; FERREIRA, G. N. Revendo o pensamento conservador. In: FERREIRA, Gabriela Nunes e BOTELHO, André (Org). Revisão do pensamento conservador: ideias e políticas no Brasil. São Paulo: Hucitec, 2010. p. 11-22.

BRASIL. Câmara dos Deputados. Projeto de Lei 5.618-A/2013. Autoriza o Poder Executivo a transformar em Projeto de Estado o programa denominado Fé na Prevenção. Disponível em <http://www.camara.gov.br/proposicoesWeb/prop_mostrarintegra;jsessionid=AE5781CFDBFBD4E8994 01EDC6C83BD85.proposicoesWebExterno2?codteor=1289973\&filename=Avulso+-PL+5618/2013>. Acesso em: 16 jun. 2017.

BRASIL. Câmara dos Deputados. Projeto de Lei 7.180/2014. Altera o art. $3^{\circ}$ da Lei $n^{\circ} 9.394$, de 20 de dezembro de 1996, que estabelece as diretrizes e bases da educação nacional. Brasília: 24 fev. 2014. Disponível em: <http://www.camara.gov.br/proposicoesWeb/prop_mostrarintegra?codteor=1230836\&\% 20filename $=P L+7180 / 2014>$. Acesso em: 16 nov. 2017.

BRASIL. Câmara dos Deputados. Projeto de Lei 867/ 2015. Inclui, entre as diretrizes e bases da educação nacional, o "Programa Escola sem Partido" - Apensado ao PL 7180/2014. Brasília: 23 mar. 2015. Disponível em: <http://www.camara.gov.br/proposicoesWeb/prop_mostrarintegra;jsessionid= E38CC6E494FC91A10743BF52B3543796.proposicoesWeb1?codteor=1317168\&filename=Avulso+PL+867/2015>. Acesso em: 10 nov. 2017.

ESCOLA SEM PARTIDO. Disponível em: <https://www.programaescolasempartido.org/>. Acesso em 16 nov. 2017.

ESPINOSA, B. R. S.; QUEIROZ, F. B. C. Breve análise sobre as redes do Escola sem Partido. In: FRIGOTTO, G. (Org). Escola "Sem" Partido. Esfinge que ameaça a educação e a sociedade brasileira. Rio de Janeiro: UERJ, LPP 2017. p. 49-62.

GADOTTI, M. Concepção dialética da educação: um estudo introdutório. São Paulo: Cortez, 1983.

MIGUEL, L. F. Da "doutrinação marxista" à "ideologia de gênero": Escola Sem Partido e as leis da mordaça no parlamento brasileiro. Direito e Práxis, Rio de Janeiro, v. 7, n. 15, p. 590-621, 2016. Disponível em: <http://www.e-publicacoes.uerj.br/index.php/revistaceaju/article/view/25163>. Acesso em: 10 nov. 2017.

MOURA, F. P. de. "Escola Sem Partido": relações entre estado, educação e religião e os impactos no ensino de História. 2016. Dissertação (Mestrado em História) - Programa de Pós-Graduação em Ensino de História Universidade Federal do Rio de Janeiro, Instituto de História, 2016.

NAGIB, M. Escola Sem Partido quem somos. Disponível em: <http://www.escolasempartido.org/ sobre/quem-somos>. Acesso em: 16 jun. 2017.

NOFFKE, A. P. Antecedentes históricos do currículo da AMOP. 2017. 242 f. Dissertação (Mestrado em Educação) - Programa de Pós-Graduação em Educação, Universidade Estadual do Oeste do Paraná, Cascavel, 2017. 
BATISTA, Eraldo Leme; NOFFKE, Ana Paula. Proposta curricular emancipadora versus movimento (conservador) escola sem partido.

ORSO. P. J. Por uma educação para além do capital e por uma educação para além da escola. In: ORSO, P. J.; GONÇALVES, S. R.; MATTOS, V. M. (Org.). Educação, estado e contradições sociais. São Paulo: Outras Expressões, 2011.

PENNA, F. O Escola sem Partido como chave de leitura do fenômeno educacional. In: FRIGOTTO, G. (Org.). Escola "Sem" Partido. Esfinge que ameaça a educação e a sociedade brasileira. Rio de Janeiro: UERJ, 2017. p. 35-48.

RAMOS, M. N. Escola sem Partido: a criminalização do trabalho pedagógico. In: FRIGOTTO, G. (Org.). Escola "Sem" Partido. Esfinge que ameaça a educação e a sociedade brasileira. Rio de Janeiro: UERJ, 2017. p. 75-86.

RIO DE JANEIRO. Alerj. Projeto de Lei no 2.974/2014. Cria, no âmbito do sistema de ensino do Estado do Rio de Janeiro, o "Programa Escola Sem Partido". 13 mai. 2014. Disponível em: <http://alerjln1.alerj.rj.gov.br/scpro1115.nsf/e4bb858a5b3d42e383256cee006ab66a/45741a7e2ccdc5 0a83257c980062a2c2>. Acesso em: 04 jun. 2017.

SAVIANI, D. Escola e democracia. São Paulo: Cortez, 1988.

SAVIANI, D. Pedagogia histórico-crítica: primeiras aproximações. 10. ed. Campinas: Autores Associados, 2008.

Eraldo Leme Batista

UNIOESTE - Campus de Cascavel

Cascavel | PR | Brasil. Contato: eraldo_batista@ hotmail.com

ORCID 0000-0003-0462-5350

Ana Paula Noffke

Secretaria de Educação do Estado do Paraná | Coordenadora

Pedagógica na Rede Pública do Estado do Paraná

Cascavel | PR | Brasil. Contato: napoliana@ hotmail.com

ORCID 0000-0002-6647-8731

Artigo recebido em: 29 mar. 2018 e aprovado em: 4 jul. 2018. 